\title{
Evaluation the Mechanical Properties of Nanofilled Composite Resin Restorative Material
}

\author{
Ibrahim M. Hamouda, Hagag Abd Elkader \\ Dental Biomaterials, Faculty of Dentistry, Mansoura and Umm Al Qura Universities, Mecca, Egypt. \\ Email:imh100@hotmail.com
}

Received January $18^{\text {th }}, 2012$; revised February $27^{\text {th }}, 2012$; accepted March $13^{\text {th }}, 2012$

\begin{abstract}
This study was designed to evaluate the wear resistance, fracture toughness and flexural strength of a nanofilled composite resin restorative material in comparison with a conventional hybrid composite resin. A total of 60 specimens were prepared from both types composite resins. Specimens were cured with a light curing device according to the manufacturer's instructions. Wear resistance was evaluated through subjecting the specimens to wear testing at 0.1 bar wet pressure against carbide abrasive counter-body using wear testing machine under water as lubricant. The test conditions were; speed $=265 \mathrm{rpm}$, load $=0.1$ bar, time $=5 \mathrm{~min}$. Flexural strength and fracture toughness were tested using three-point bending test in universal testing machine at a cross head speed of $2 \mathrm{~mm} / \mathrm{min}$ until failure occurred. The nanofilled composite resin material exhibited higher wear resistance than the hybrid composite resin material. On the other hand, there were no significant differences between the two materials in values of flexural strength and fracture toughness. It was concluded that the nanofilled composite resin was harder but it does not stronger than the conventional hybrid composite resin.
\end{abstract}

Keywords: Nanofilled; Wear; Flexural Strength; Toughness; Composite Resin

\section{Introduction}

Resin composites are increasingly used for restorative purposes because of good esthetic and the capability of establishing a bond to enamel and dentin. The color stability, wear, fracture resistance of these materials have been greatly improved since their introduction about 50 years ago [1]. However, like all dental materials, composites have their own limitations, such as the gap formation caused by polymerization contraction during setting, leading to marginal discoloration and leakage [2]. In addition, they are subjected to higher wear rates than ceramics, and although some composites have wear rates similar to amalgam, many have higher wear rates [3].

Improvements of mechanical properties of the composite have permitted its use in posterior teeth with greater reliability than was the case some years ago. This improvement included; development of smaller particle sizes of filler, better bonding systems, curing refinements and sealing systems [4]. Composite resin materials have progressed from macrofills to microfills and from hybrids to microhybrids, and new materials such as packable and nanofilled composites have been introduced to the dental market [5-7]. Each type of composite resin has certain advantages and limitations. The universal hybrid composites provide the best general blend of good material properties and clinical performance for routine anterior and posterior restorations [8].

The recently introduced nanofilled composite has been introduced to the dental market, which has been produced with nanofiller technology and formulated with nanomer and nanocluster filler particles. Nanomers are discrete nanoagglomerated particles of $20-75 \mathrm{~nm}$ in size, and nanoclusters are loosely bound agglomerates of nano-sized particles. The combination of nanomer-sized particles and nanocluster formulations reduces the interstitial spacing of the filler particles and, therefore, provides increased filler loading, better physical properties, and improved polish retention [9]. Dental composites based on nanofill and ormocer (organically modified ceramics) technologies were recently introduced to the dental profession. Nanofilled composite was mentioned in early 1990s but the first commercial product (Filtek Supreme, 3M-ESPE) was launched in late 2002 [4].

Accordingly, this investigation was designed to evaluate the mechanical properties of nanofilled composite resin in comparison with the conventional hybrid composite resin regarding the wear resistance, fracture toughness and flexural strength. 


\section{Materials and Methods}

The materials used in this study are presented in Table $\mathbf{1 .}$

\subsection{Evaluation of Wear Resistance}

Ten specimens were prepared from each type of composite resin $(8 \mathrm{~mm}$ length $\times 4 \mathrm{~mm}$ width $\times 2 \mathrm{~mm}$ thickness $)$ using a rectangular split Teflon mold. The mold was covered with acetate strips. A glass slab was placed over the mold under pressure to remove the excess material. Each specimen was exposed to light curing unit according to the manufacturers' instructions. The specimens were removed from their molds and stored in distilled water for 24 hours at $37^{\circ} \mathrm{C}$. Metal blocks (20 blocks in dimensions of $10 \mathrm{~mm} \times 10 \mathrm{~mm} \times 7.5 \mathrm{~mm}$ ) were prepared, each specimen was bonded on a metal block on the side of $(10 \mathrm{~mm} \times 7.5 \mathrm{~mm})$ dimensions using cyanoacrylate adhesive according to the specifications of the testing machine .The specimens were weighted before and after application of wearing The specimens were subjected to wear testing at 0.1 bar wet pressure against carbide abrasive counter-body using wear testing machine (Tribometer testing machine, Germany) under water as lubricant. The test conditions were; speed $=265 \mathrm{rpm}$, load $=0.1$ bar, time $=5 \mathrm{~min}$. The weight loss in gram was evaluated.

\subsection{Evaluation of the Fracture Toughness}

Twenty rectangular specimens were prepared, 10 from each type of composite resin $(30 \mathrm{~mm}$ in length, $5 \mathrm{~mm}$ in width and $2.5 \mathrm{~mm}$ in thickness). The mold used was split stainless steel, contains sharp notch at its center and extending to half of the specimen width. The material was packed into the mold that was supported with a glass slab.
Another glass slab was placed on the top of the mold. Light pressure was applied to expel the excess material and trapped air. The top and bottom surfaces of the specimens were then light polymerized in five overlapping irradiations of 30 seconds. Specimens were stored in distilled water at $37^{\circ} \mathrm{C}$ until they were tested by threepoint bending test in universal testing machine (Lloyd, type 500, England) with a cross head speed of $2 \mathrm{~mm} / \mathrm{min}$ until failure occurred. The intensity factor, KIC (MPa. $\sqrt{m})$, was obtained from the peak load $\left(P_{Q}\right)$ and sample configuration by the following equation [10]:

$$
\begin{aligned}
& K_{I C}=\left[\left(P_{Q} \cdot S\right) /\left(B W^{1.5}\right)\right] \times f(a / w) \\
& f(a / w)=3(a / w)^{0.5} \\
& \frac{1.99-(a / w)(1-a / w)\left\{2.15-3.93 a / w+2.7(a / w)^{2}\right\}}{2(1+2 a / w)(1-a / w)^{1.5}}
\end{aligned}
$$

where, $P_{Q}$ is the peak load $(\mathrm{N}), S$ is the span $(\mathrm{m}), B$ is the specimen thickness $(\mathrm{m}), a$ is the crack length, $w$ is the specimen width $(\mathrm{m})$ and $(a / w=1 / 2)$.

\subsection{Evaluation of the Flexural Strength}

A total of 20 rectangular specimens, 10 from each type of composite resin measuring $(25 \mathrm{~mm}$ length, $2 \mathrm{~mm}$ width and $2 \mathrm{~mm}$ thickness). Specimens were light polymerized in three over lapping irradiations of 40 seconds. After light polymerization, the flash was removed. Then, the specimens were stored in deionized water at $37^{\circ} \mathrm{C}$ until used. The flexural strength was measured using a universal testing machine via a three bending test. A cylin-

\begin{tabular}{|c|c|c|c|c|c|}
\hline Materials & Type & Composition & Batch No & Manufacturers & \\
\hline $\begin{array}{l}\text { Filtek }^{\mathrm{TM}} \\
\text { Supreme }\end{array}$ & $\begin{array}{l}\text { Light curing } \\
\text { nanofilled } \\
\text { composite resin }\end{array}$ & $\begin{array}{l}\text { Monomer matrix contains Bis-GMA, urethane } \\
\text { dimethacrylate, triethylene glycol imethacrylate } \\
\text { and bis-EMA resin, inorganic filler particles are } \\
\text { a ombination of aggregated zirconia/silica cluster and } \\
\text { a non-agglo merated/non-aggregated silica filler }\end{array}$ & 3910A3.5B & $\begin{array}{l}\text { 3M ESPE Dental } \\
\text { Products St. Paul, } \\
\text { MN } 55144\end{array}$ & \\
\hline Prime-Dent $^{\circledR}$ & & & Chicago, IL & BelmontAve. & \\
\hline \multirow{3}{*}{$\begin{array}{l}\text { Aper }{ }^{\mathrm{TM}} \text { Single } \\
\text { Bond2 Adhesive }\end{array}$} & & 60618 & & & \\
\hline & $\begin{array}{l}\text { Light curing } \\
\text { Bonding agent }\end{array}$ & $\begin{array}{l}\text { Adhesive containing } 10 \% \text {, } \\
5 \mathrm{~nm} \text { colloidal filler }\end{array}$ & 4BK51202 & $\begin{array}{l}\text { 3M ESPE Dental } \\
\text { Products St. } \\
\text { PaulMN }\end{array}$ & \\
\hline & & & 5544 & & \\
\hline SDI Super Etch & Etchant Gel & 37 wt $\%$ phosphoric acid & 00601 & SDI & \\
\hline
\end{tabular}
drical aluminum block with tapered edge was attached to

Table 1. Materials used in this study. 
the upper part of the machine and used to apply load at the center of the sample. The load was applied in a compression at a cross head speed of $2 \mathrm{~mm} / \mathrm{min}$ until failure occurred. The maximum load at fracture was recorded electronically in Newton $(\mathrm{N})$ and flexural strength $(\mathrm{MPa})$ was calculated using the following formula [11]:

$$
\sigma=3 P_{f} L / 2 W H^{2}
$$

where $P_{f}$ is the applied load, $L$ is length of specimen, $W$ is the width of specimen, $H$ is the height of specimen.

\subsection{Statistical Analysis}

The data obtained were tabulated for statistical analysis which was conducted using SPSS (Statistical Package for Social Science) version 10. t-test was used to detect the significant difference between the variables tested in this study.

\section{Results}

\subsection{Results of the Mechanical Properties}

The results of the wear test are presented in Table 2. In general, nanofilled composite have low wear value than that of hybrid composite. The t-test demonstrated a significant difference between the mean wear values of nanofilled composite (Filtek Supreme) and hybrid composite (Prime-Dent) $(\mathrm{P} \leq 0.000)$.

The results of the fracture toughness test are presented in Table 3. The fracture toughness of nanofilled composite resin was higher than that of the hybrid composite. The t-test demonstrated no significant difference between the mean fracture toughness of nanofilled composite (Filtek Supreme) and hybrid composite (Prime-Dent) (P $>0.05)$.

The mean flexural strength (MPa) of nanofilled composite (Filtek Supreme) and hybrid composite (PrimeDent) are presented in Table 4. The flexural strength of nanofilled composite resin was higher than that of the

Table 2. Mean weight loss (mg) of nanofilled and hybrid composite resins.

\begin{tabular}{cccc}
\hline Materials & Mean $\pm \mathrm{SD}$ & t-value & P-value \\
\hline Nanofilled Composite & $25.6 \pm 2.7$ & -14.26 & 0.000 \\
Hybrid Composite & $74.3 \pm 4.8$ & & \\
\hline
\end{tabular}

Table 3. The mean fracture toughness (MPa. $\sqrt{m}$ ) of nanofilled and hybrid composite resins.

\begin{tabular}{cccc}
\hline Materials & Mean \pm SD & t-value & P-value \\
\hline $\begin{array}{ccc}\text { Nanofilled Composite } \\
\text { Hybrid Composite }\end{array}$ & $6.54 \pm 1.4$ & 0.531 & 0.602 \\
\hline
\end{tabular}

Table 4. The mean flexural strength (MPa) of nanofilled and hybrid composite resins.

\begin{tabular}{cccc}
\hline Materials & Mean \pm SD & t-value & P-value \\
\hline Nanofilled Composite & $93.68 \pm 16.8$ & 0.625 & 0.54 \\
Hybrid Composite & $89.85 \pm 9.6$ & & \\
\hline
\end{tabular}

hybrid composite. The t-test demonstrated no significant difference between the mean flexural strength of nanofilled composite (Filtek Supreme) and hybrid composite (Prime-Dent) $(\mathrm{P}>0.05)$.

\subsection{Correlations}

\subsubsection{Correlation between Wear and Fracture Toughness}

There was a significant positive correlation between wear and fracture toughness of nanofilled composite resin. Pearson correlation was $0.685^{*}$ and Sig. (2-tailed) was 0.029 . Correlation was significant at the 0.05 level (2tailed). There was a positive correlation between wear and fracture toughness of hybrid composite resin but not significant. Pearson correlation was 0.444 and Sig. (2tailed) was 199.

\subsubsection{Correlation between Wear and Flexural Strength}

There were a negative correlation between wear and flexural strength of both nanofilled and hybrid composite resins. Pearson correlations were -0.337 and -0.296 respectively and Sig. (2-tailed) were 0.340 and 0.466 respectively.

\subsubsection{Correlation between Fracture Toughness and Flexural Strength}

There were a negative correlation between fracture toughness and flexural strength of both nanofilled and hybrid composite resins. Pearson correlations were -0.453 and -0.273 respectively and Sig. (2-tailed) were 0.189 and 0.446 respectively.

\section{Discussion}

A new brand of composite resins called "nanofilled composites" has been introduced to the dental market, which has been produced with nanofiller technology and formulated with nanomer and nanocluster filler particles Nanomers are discrete nanoagglomerated particles of 20 - $75 \mathrm{~nm}$ in size, and nanoclusters are loosely bound agglomerates of nano-sized particles. The manufacturer suggests the combination of nanomer-sized particles and nanocluster formulations reduces the interstitial spacing of the filler particles and, therefore, provides increased filler loading, better physical properties and improved 
polish retention [9].

Two-body abrasion test have been used to rank the wear resistance of restorative materials. The results showed that, nanofilled composite resin (Filtek Supreme) which has lower particle size $(5-20 \mathrm{~nm})$ has lower wear in comparison to conventional hybrid composite resin (Prime-Dent) which has larger average particle size (1.4 $\mu \mathrm{m})$ and there is a high significance between the tested materials. Reducing the filler particle size and increasing the filler loading, the wear resistance has been improved $[12,13]$.

The type of filler particles also may play a role in the wearing process, the zirconia/silica containing resin composite (filtek suprme) showed better wear resistance than barium glass filler containing hybrid composite resin (prime-dent). It was reported that, although the hydrolytic degradation of the filler particles could not be proven to be the primary cause for the clinical wear process, it is important for selection of the materials, from a clinical viewpoint, using a silica filled composite has been recommended instead of a glass-filled composite that leaches more filler elements and degrades faster [14].

For optimum physical and mechanical properties of the restoration, the residual monomer content should be minimized and the percentage of conversion to polymer maximized [15]. It has been claimed that in nanofilled composite resin the majority of TEGDMA (tri [ethylene glycol] dimethacrylate) has been replaced with UDMA and Bis-EMA (Bisphenol A polyethylene glycol diether dimethacrylate). Both of these resins have a higher molecular weight and fewer double bonds per unit, which improves the degree of cure of the polymer matrix and therfore, wear resistance [9]. The use of finer particles of filler results in decreased inter-particle spacing and reduced wear [16]. Good bond between the filler and matrix through the silane coupling agent and increasing the filler surface area by using finer particles of filler improved the wear of dental composites [17].

Good fracture toughness of dental composite resins which is a measure of its ability to retard crack initiation or ropagation, is important for the prevention of marginal breakdown and is possibly related to good wear resistance [18]. The results of fracture toughness in the present investigation revealed that both types of composite resins had nearly equal fracture toughness values. However, nanofilled composite resin had slightly increased fracture toughness value than hybrid composite resin, there was no significant difference between the two materials. Addition of filler to the polymer matrix causes a reinforcement and provides additional toughening mechanisms. The matrix is reinforced by transferring stress to the strong particulate fillers, thus enhancing its ability to absorb energy and become more fracture-resistance. The stress transfer and reinforcement appear to be opti- mal for composites containing high volume fractions of fillers that are well-coupled to the resin matrix [19]. The fillers provide several toughening mechanisms, including crack pinning and microcrack-induced toughening. The latter has recently been shown to occur in dental composites [20,21].

Due to the more extensive array of toughening mechanisms available to a filled material, attaining maximum fracture toughness is dependent upon having sufficient adherent fillers in the composite structure. Minimizing degree of conversion, filler volume fraction, or filler/ matrix bonding causes the resin matrix to bear a greater proportion of the stress imposed during loading and results in a reduction in $\mathrm{K}_{\mathrm{Ic}}$. Therefore, for a given composite, any event which causes the properties of the resin matrix to dominate will necessarily result in a reduction in the $\mathrm{K}_{\mathrm{Ic}}$ [22]. Mitra and Brain (2003) found that, the use of spheroidal nanocluster fillers with their broad particle distribution enabled to obtain high filler loading, desirable handling characteristics and physical properties comparable with those of commercial hybrid composites [23].

Flexural strength test was performed using the threepoint bending test because of its lower standard deviation, the lower coefficient of variation and the less complex crack distribution produced by it when compared to those produced by other test designs, such as the biaxial flexural test [24]. The results of the present study showed that, there was slight increase in flexural strength value of nanofilled composite resin (Filtek Supreme). However, this was statistically insignificant. Since both types of composites evaluated contained nearly equal filler volume content of about $60 \%$ so that the flexural strength of Flitek Supreme nanofilled composites are statistically equivalent to or higher than that of the hybrid composites tested. There is a correlation between mechanical properties and filler volume, increasing the filler volume improve the mechanical properties including flexural strength [25].

\section{Conclusions}

Within the limitations of this study, the following cauld be concluded:

1) Nanofilled composite resin exhibited higher wear resistance than that of hybrid composite resin materials.

2) There is no significant differences among the materials tested regarding the fracture toughness and flexural strength.

\section{REFERENCES}

[1] J. Mahart and R. Hickel "Esthetic Compomer Restorations in Posterior Teeth Using a New All-in-One Adhesives," Journal of Esthetic and Restorative Dentistry, Vol. 
11 , No. 5 , 1999, pp. 250-258. doi:10.1111/j.1708-8240.1999.tb00406.x

[2] J. F. Roulet, "The Problems Associated with Substituting Composite Resins for Amalgam: A Status Report on Posterior Composites," Journal of Dentistry, Vol. 6, No. 3, 1988, pp. 101-103. doi:10.1016/0300-5712(88)90001-2

[3] W. B. Wayne, A. L. Mark, L. E. Robert and L. Paul, "Comparison of Laboratory and Clinical Wear Rates of Resin Composites," Quintessence International, Vol. 35, No. 4, 2004, pp. 269-274.

[4] S. C. Bayne, H. O. Heymann and E. J. Swift, "Update on Dental Composite Restoration," Journal of the American Dental Association, Vol. 125, No. 6, 1994, pp. 687-701.

[5] N. Attar, "Effect of Finishing and Polishing Procedures on the Surface Roughness of Composite Resin Materials," Journal of Contemporary Dental Practice, Vol. 8, No. 1, 2007, pp. 27-35.

[6] J. Mahart, H. Y. Chen and R. Hickel, "The Suitability of Packable Resin-Based Composites for Posterior Restorations," Journal of the American Dental Association, Vol. 132, No. 5, 2001, pp. 639-645.

[7] N. Attar and M. D. Turgut, "Fluoride Release and Uptake Capacities of Fluoride Releasing Restorative Materials," Operative Dentistry, Vol. 28, No. 4, 2003, pp. 395-402.

[8] K. F. Leinfelder, "Posterior Composite Resins: The Materials and Their Clinical Performance," Journal of the American Dental Association, Vol. 126, No. 5, 1995, pp. 663-672.

[9] 3M Dental Products Filtek ${ }^{\mathrm{TM}}$ Supreme Universal Restorative System, Technical Product Profile St. Paul MN 55144-1000, 2002.

[10] D. B. Esteban, Y. Mahrkh and A. C. Angelo, "Fracture Toughness of Nine Flowable Resin Composites," Journal of Prosthetic Dentistry, Vol. 89, No. 3, 2003, pp. 261-267. doi:10.1067/mpr.2003.33

[11] N. Attar, L. E. Tam and D. McComb, "Flow, Strength, Stiffness and Radiopacity of Flowable Resin Composites," Journal of the Canadian Dental Association, Vol. 69 , No. 8, 2003, pp. 516-521.

[12] S. Suzuki, K. F. Leinfelder, K. Kawai and Y. Tsuchitani, "Effect of Particle Variation on Wear Rates of Posterior Composites," American Journal of Dentistry, Vol. 8, No. 4, 1995, pp. 173-178.

[13] J. R. Condonand and J. L. Ferracane, "In Vitro Wear of Composite with Varied Cure, Filler Level, and Filler Treatment," Journal of Dental Research, Vol. 76, No. 7, 1997, pp. 1405-1411. doi:10.1177/00220345970760071101

[14] K. J. Söderholm, P. Lambrechts, P. Sarrett, Y. Abe, M. C. Yang, R. Labella, E. Yildiz and G. Willems, "Clinical Wear Performance of Eight Experimental Dental Composites over Three Years Determined by Two Measuring
Methods," European Journal of Oral Sciences, Vol. 109, No. 4, 2001, pp. 273-281. doi:10.1034/j.1600-0722.2001.00064.x

[15] G. Willems, P. Lambrechts, M. Braem and G. Vanherle, "Composite Resins in the $21^{\text {st }}$ Century," Quintessence International, Vol. 24, No. 6, 1993, pp. 641-658.

[16] K. D. JǾgensen and E. Asmussen, "Occlusal Abrasion of a Composite Restorative Resin with Ultra-Fine Filler," Quintessence International, Vol. 9, No. 6, 1978, pp. 7378.

[17] K. J. Söderholm and S. W. Shang, "Molecular Orientation of Silane at the Surface of Colloidal Silica," Journal of Dental Research, Vol. 72, No. 6, 1993, pp. 1050-1054. doi:10.1177/00220345930720061001

[18] R. M. Pilliar, R. Vowles and D. F. Williams, "The Effect of Environmental Aging on the Fracture Toughness of Dental Composites," Journal of Dental Research, Vol. 66, No. 3, 1987, pp. 722-726. doi:10.1177/00220345870660030301

[19] J. Spanoudakis and R. J. Young, "Crack Propagation in a Glass Particle-Filled Epoxy Resin Part 1 Effect of Particle Volume Fraction and Size," Journal of Materials Science, Vol. 19, No. 2, 1984, pp. 473-486. doi:10.1007/BF02403234

[20] R. J. Young and P. W. R. Beaumont, "Failure of Brittle Polymers by Slow Crack Growth Part 2 Failure Processes in a Silica Particle-Filled Epoxy Resin Composite," Journal of Materials Science, Vol. 10, No. 8, 1975, pp. 13431350. doi:10.1007/BF00540824

[21] K. H. Kim, J. H. Park, Y. Imai and T. Kishi, "Fracture Toughness and Acoustic Emission Behavior of Dental Composite Resins," Engineering Fracture Mechanics, Vol. 40, No. 4-5, 1991, pp. 811-819. doi:10.1016/0013-7944(91)90238-V

[22] J. L. Ferracane and V. A. Marker, "Solvent Degradation and Reduced Fracture Toughness in Aged Composites," Journal of Dental Research, Vol. 71, No. 1, 1992, pp. 1319. doi:10.1177/00220345920710010101

[23] S. B. Mitra and N. Brain, "An Application of Nanotechnology in Advanced Dental Materials," Journal of the Canadian Dental Association, Vol. 134, No. 10, 2003, pp. 1382-1390

[24] S. M. Cung, A. U. J. Yab, S. P. Chandra and C. T. Lim, "Flexural Strength of Ental Composite Restoratives: Comparison of Biaxial and Three-Point Ending Test," Journal of Biomedical Materials Research Part B Applied Biomaterials, Vol. 71, No. 2, 2004, pp. 278-283.

[25] J. L. Ferracane, "In Vitro Evaluation of Composite Resins: Structure-Property Relations," Transactions of the Academy of Dental Materials, Vol. 2, 1989, pp. 6-8. 